\title{
The cytokine language of monocytes and macrophages in systemic sclerosis
}

\author{
Romy B Christmann and Robert Lafyatis* \\ See related research by Higashi-Kuwata et al., http://arthritis-research.com/content/12/4/R128
}

\begin{abstract}
Many important observations suggest monocyte/ macrophage involvement in systemic sclerosis (SSc). A high concentration of immune mediators, such as IL-6, $\mathrm{IL}-10$ and IL-13, the infiltration of mononuclear cells in affected organs and the production of autoantibodies suggest that immune system dysfunction drives SSc pathogenesis. The recently reported study by Higashi-Kuwata and colleagues, in light of other observations, provides further insight into activation of macrophages/monocytes in SSc patients, suggesting that these cells undergo distinct activation pathways. These results emphasize the need for more detailed analyses of the several markers now defined in SSC peripheral blood mononuclear cells and tissues to better define the cytokine language speaking to monocytes/macrophages in SSc that promote vascular injury and tissue fibrosis.
\end{abstract}

In a recent issue of Arthritis Research and Therapy, Higashi-Kuwata and colleagues elegantly showed evidence that macrophages/monocytes with a profibrotic profile may be involved in the pathogenesis of systemic sclerosis (SSc) [1]. Early studies of the histopathology of SSc showed that macrophages are found in dermal perivascular and interstitial infiltrates, particularly prominent in perivascular infiltrates of early diffuse SSc skin [2], and in SSc-associated interstitial lung disease [3]. Tissue macrophages show markers of activation in SSc skin expressing increased HLA-DR and plateletderived growth factor type B receptor [4] and MCP-1/ CCL2 [5], and in bronchoalveolar lavage fluid secreting increased IL-8 [6] and endothelin-1 [7].

*Correspondence: lafyatis@bu.edu

Boston University School of Medicine, Rheumatology Section, Boston University Medical Campus E5, 72 E Concord Street, Boston, MA 02118, USA
More recent studies have shown that SSc monocytes express allograft inhibitory factor-1 [8]. Data from our group indicate that allograft inhibitory factor-1 expression in circulating monocytes is part of an interferonresponsive gene expression signature in SSc patients [9] (RBC and RL, unpublished observations). Strikingly, in patients showing upregulated interferon-responsive genes, all $\mathrm{CD} 14^{+}$monocytes expressed increased sialoadhesin, suggesting that interferon activates the entire monocyte population. In addition, several genes associated with monocyte/macrophage recruitment and differentiation were overexpressed in recent microarray analyses of SSc peripheral blood mononuclear cells, compared with healthy controls [10].

Macrophages exposed to IFNY undergo classical activation, referred to as M1, and have powerful antimicrobial activity. In contrast, IL-4 and IL-13 (Th2 cytokines) switch macrophages to a M2 phenotype, enhancing endocytosis and pinocytosis, repressing proinflammatory cytokines and stimulating tissue remodeling [11]. Although the M1/M2 paradigm serves as a useful extension of Th1/Th2-mediated immune responses, it is inadequate for completely understanding monocyte responses to cytokines and their differentiation into macrophages, because many other mediators impact on this process, including glucocorticoids, toll-like receptor-4 ligands and IL-10 [11]. Although more complex models of monocyte maturation into macrophages have been developed - such as M2a (IL-4/IL-13 activated), M2b (immune complex or toll-like receptor activated) and M2c (IL-10 or glucocorticoid activated) [12] - it may be more appropriate to consider monocytes as responding to a cytokine/innate immune mediator language. Perhaps most relevant in autoimmune disease is the role of type I interferons, as they are also able to activate monocytes stimulating dendritic cell differentiation in vitro and, in a model of chronic inflammation, blocking maturation of Ly6C ${ }^{\text {hi }}$ monocytes into Ly6C ${ }^{\text {lo }}$ resident monocytes typically recruited to non-inflamed tissues [13].

In this context, Higashi-Kuwata and colleagues found that CD68, a pan-macrophage indicator, and two markers of macrophage activation, CD163 and CD204, were 
increased in SSc patients. Specifically in the skin, these activation markers were highly expressed in perivascular regions and between thickened collagen bundles. As M2 macrophages are important sources of many cytokines, such as transforming growth factor beta, they may be responsible for the fibrotic phenotype of SSc patients [11]. Although these markers are suggestive of alternative macrophage activation, CD163 can also be stimulated by IL-10 [14] and the M1 versus M2 phenotype association with CD204 remains unclear [15]. Of note, however, CD204-deleted mice fail to develop silica-induced fibrosis consistent with a key role for this scavenger receptor in profibrotic disease [16]. Further investigation into the role of these surface markers and IL-4/IL-13 monocyte/macrophage activation in SSc is therefore clearly needed.

The authors also analyzed CD14 $4^{+}$populations in the blood of these patients. Interestingly, they found a minor CD14 ${ }^{\text {hi }}$ population of circulating monocytes in SSc patients. These results are notable because $\mathrm{CD} 14^{++} \mathrm{CD} 16^{-} /$ CX $3 C R 1^{\text {lo }}$ versus $\mathrm{CD} 14^{+} \mathrm{CD} 16^{+} / \mathrm{CX} 3 \mathrm{CR} 1^{\mathrm{hi}}$ in humans (and Ly- $6^{\text {hi }} / \mathrm{Gr}-1^{\text {hi }}$ versus Ly- $6^{\text {lo }} / \mathrm{Gr}-1^{\text {lo }}$ in the mouse) have been described to represent distinct monocyte subpopulations: the former $\left(\mathrm{CD} 14^{++} \mathrm{CD} 16^{-}\right)$turning into tissue macrophages and possibly dendritic cells or maturing into $\mathrm{CD} 14^{+} \mathrm{CD} 16^{+}$, the major circulating monocyte population; the latter $\left(\mathrm{CD} 14^{+} \mathrm{CD} 16^{+}\right)$turning into resident tissue monocyte/macrophages $[17,18]$. The CD14 ${ }^{\text {hi }}$ monocyte population described by Higashi-Kuwata and colleagues thus might be normally short-lived $\mathrm{CD} 14^{++} \mathrm{CD} 16^{-}$ monocytes destined for inflammatory sites. Based on the recent observations in mice [13], type I interferon might play a role in this process by blocking maturation of $\mathrm{CD}^{2} 4^{+} \mathrm{CD} 16^{-}$into $\mathrm{CD} 14^{+} \mathrm{CD} 16^{+}$monocytes, and stimulating CCR2 expression and recruitment into inflamed tissues. This hypothesis contrasts with the increased CX3CR $1^{+}$cells reported in SSc previously [19], however, as CX3CR $1^{+}$is a marker for $\mathrm{CD} 14^{+} \mathrm{CD} 16^{+}$cells and is thought responsible for recruiting these cells as resident tissue macrophages. Both, ie. $\mathrm{CD} 14^{+} \mathrm{CD} 16^{+} \mathrm{CX} 3 \mathrm{CR} 1^{+}$and CD14 ${ }^{++} \mathrm{CD} 16^{-} \mathrm{CXCR} 1^{-}$cells probably represent distinct monocyte populations, and the resolution of this dilemma is likely to occur through understanding better the underlying cytokine/innate immune stimuli affecting SSc monocytes.

Higashi-Kuwata and colleagues further reported that the $\mathrm{CD} 14^{\text {hi }}\left(\mathrm{CD} 14^{\text {bright }}\right.$ or $\left.\mathrm{CD} 14^{++}\right)$population in SSc patients expresses higher levels of CD163 and CD204. The expression of CD163 was greater in SSc patients, whereas CD204 did not distinguish SSc from the healthy controls. In order to further define the CD14 $4^{\mathrm{h}}$ population, the authors performed triple staining - confirming that a minor $\mathrm{CD} 14^{\mathrm{hi}} \mathrm{CD} 163^{+} \mathrm{CD} 204^{+}$population is increased in SSc patients.
Together these results suggest that SSc peripheral blood mononuclear cells develop an anti-inflammatory and profibrotic M2 phenotype. Further studies will be needed to understand the signals causing these changes and whether they contribute to vascular injury and fibrosis.

\section{Abbreviations}

IFN, interferon; IL, interleukin; SSC, systemic sclerosis; Th, T-helper type.

\section{Competing interests}

The authors declare that they have no competing interests.

Published: 29 October 2010

\section{References}

1. Higashi-Kuwata N, Jinnin M, Makino T, Fukushima S, Inoue Y, Muchemwa FC, Yonemura Y, Komohara Y, Takeya M, Mitsuya $\mathrm{H}, \mathrm{Ihn} \mathrm{H}$ : Characterization of monocyte/macrophage subsets in the skin and peripheral blood derived from patients with systemic sclerosis. Arthritis Res Ther 2010, 12:R128.

2. Kraling BM, Maul GG, Jimenez SA: Mononuclear cellular infiltrates in clinically involved skin from patients with systemic sclerosis of recent onset predominantly consist of monocytes/macrophages. Pathobiology 1995, 63:48-56.

3. Rossi GA, Bitterman PB, Rennard SI, Ferrans VJ, Crystal RG: Evidence for chronic inflammation as a component of the interstitial lung disease associated with progressive systemic sclerosis. Am Rev Respir Dis 1985, 131:612-617.

4. Klareskog L, Gustafsson R, Scheynius A, Hallgren R: Increased expression of platelet-derived growth factor type $B$ receptors in the skin of patients with systemic sclerosis. Arthritis Rheum 1990, 33:1534-1541.

5. Yamamoto T, Eckes B, Hartmann K, Krieg T: Expression of monocyte chemoattractant protein-1 in the lesional skin of systemic sclerosis. J Dermatol Sci 2001, 26:133-139.

6. Crestani B, Seta N, Palazzo E, Rolland C, Venembre P, Dehoux M, Boutten A, Soler P, Dombret MC, Kahn MF: Interleukin-8 and neutrophils in systemic sclerosis with lung involvement. Am J Respir Crit Care Med 1994, 150(5 Pt 1):1363-1367.

7. Abraham DJ, Vancheeswaran R, Dashwood MR, Rajkumar VS, Pantelides P, Xu SW, du Bois RM, Black CM: Increased levels of endothelin-1 and differential endothelin type $A$ and $B$ receptor expression in scleroderma-associated fibrotic lung disease. Am J Pathol 1997, 151:831-841.

8. Del Galdo F, Maul GG, Jimenez SA, Artlett CM: Expression of allograft inflammatory factor 1 in tissues from patients with systemic sclerosis and in vitro differential expression of its isoforms in response to transforming growth factor beta. Arthritis Rheum 2006, 54:2616-2625.

9. York MR, Nagai T, Mangini AJ, Lemaire R, van Seventer JM, Lafyatis R: A macrophage marker, Siglec-1, is increased on circulating monocytes in patients with systemic sclerosis and induced by type I interferons and toll-like receptor agonists. Arthritis Rheum 2007, 56:1010-1020.

10. Pendergrass SA, Hayes E, Farina G, Lemaire R, Farber HW, Whitfield ML, Lafyatis R: Limited systemic sclerosis patients with pulmonary arterial hypertension show biomarkers of inflammation and vascular injury. PLoSOne 2010, Epub ahead of print.

11. Martinez FO, Helming L, Gordon S: Alternative activation of macrophages: an immunologic functional perspective. Annu Rev Immuno/ 2009, 27:451-483.

12. Mantovani A, Sica A, Sozzani S, Allavena P, Vecchi A, Locati M: The chemokine system in diverse forms of macrophage activation and polarization. Trends Immunol 2004, 25:677-686.

13. Lee PY, Li Y, Kumagai Y, Xu Y, Weinstein JS, Kellner ES, Nacionales DC, Butfiloski EJ, van Rooijen N, Akira S, Sobel ES, Satoh M, Reeves WH: Type I interferon modulates monocyte recruitment and maturation in chronic inflammation. Am J Pathol 2009, 175:2023-2033.

14. Sulahian TH, Högger P, Wahner AE, Wardwell K, Goulding NJ, Sorg C, Droste A, Stehling M, Wallace PK, Morganelli PM, Guyre PM: Human monocytes express CD163, which is upregulated by IL-10 and identical to p155. Cytokine 2000, 12:1312-1321.

15. Jozefowski S, Arredouani M, Sulahian T, Kobzik L: Disparate regulation and function of the class A scavenger receptors SR-AI/II and MARCO. J Immunol 
2005, 175:8032-8041.

16. Beamer CA, Holian A: Scavenger receptor class A type I/II (CD204) null mice fail to develop fibrosis following silica exposure. Am J Physiol 2005, 289:L186-L195.

17. Geissmann F, Jung S, Littman DR: Blood monocytes consist of two principal subsets with distinct migratory properties. Immunity 2003, 19:71-82.

18. Gordon S: Macrophage heterogeneity and tissue lipids. J Clin Invest 2007, 117:89-93.
19. Hasegawa M, Sato S, Echigo T, Hamaguchi Y, Yasui M, Takehara K: Up regulated expression of fractalkine/CX3CL1 and CX3CR1 in patients with systemic sclerosis. Ann Rheum Dis 2005, 64:21-28.

doi:10.1186/ar3167

Cite this article as: Christmann RB, Lafyatis R: The cytokine language of monocytes and macrophages in systemic sclerosis. Arthritis Research \& Therapy 2010, 12:146. 